\title{
O DIREITO AO ESQUECIMENTO COMO TUTELA DOS DIREITOS DA PERSONALIDADE NA SOCIEDADE DA INFORMAÇÃO: UMA ANÁLISE SOB A ÓTICA DO DIREITO CIVIL CONTEMPORÂNEO
}

\section{THE RIGHT TO BE FORGOTTEN AS A PROTECTION OF PERSONALITY RIGHTS IN THE INFORMATION SOCIETY: AN ANALYSIS FROM THE PERSPECTIVE OF CONTEMPORARY CIVIL RIGHTS}

\author{
Sthéfano BRUno SANTOS Divino \\ Graduando do curso de Direito do Centro Universitário de Lavras (Unilavras).Lavras, MG, Brasil. \\ sthefanobloog@hotmail.com \\ LUCAS ANDRÉ Viegas CARVALHO de SiQUEIRA \\ Doutor em Direito pela Pontifícia Universidade Católica de São Paulo (PUC/SP). Professor titular do curso de \\ graduação em Direito da da Universidade Santa Cecilia (UNISANTA). Lavras, MG, Brasil.
}

aroeiradopantanal@gmail.com

\section{RESUMO}

A evolução tecnológica encontra-se como característica intrínseca da sociedade contemporânea. A partir dessa premissa, o presente artigo tem como objetivo analisar 0 instituto do direito ao esquecimento, a fim de identificar a sua incidência e aplicabilidade, seja no direito brasileiro, seja no direito comparado, no âmbito da sociedade da informação. O problema encontra-se na falta de respaldo legal para sua utilização no sistema jurídico brasileiro. Contudo, através da obtenção de dados através da pesquisa bibliográfica e o uso dos métodos empírico dialético, empírico generalizado e dedutivo, concluiu-se pela possibilidade da aplicação deste instituto visando à proteção e tutela dos direitos da personalidade, desde que preenchidos os requisitos para tanto, fazendo com que a tutela jurídica inibitória do Poder Judiciário recaia sobre tais direitos e efetive o cumprimento e satisfação da aplicação do direito ao esquecimento.

Palavras-chave: Direito ao esquecimento; direito civil contemporâneo; direito e internet; sociedade da informação.

\begin{abstract}
Technological evolution is like an intrinsic feature of contemporary society. From this premise, this article aims to analyze the institute of the right to be forgotten in order to identify its incidence and applicability, both in Brazilian laws and in comparative law, in the context of information society. The problem lies in the lack of legal support for its use in the Brazilian legal system. However, by obtaining data through bibliographical research and the use of the dialectical empirical, generalized empirical and deductive methods, it concluded that there is the possibility of applying this institute aiming the protection and safeguarding the rights of personality, if filled the requirements to it, making the inhibitory legal protection of the Judiciary take place on these rights and effect the fulfillment and satisfaction of the application of the right to be forgotten.
\end{abstract}

Keywords: Right to be forgotten; Contemporary civil rights; rights and internet; information society. 


\section{SUMÁRIO}

INTRODUÇÃO; 10 DIREITO AO ESQUECIMENTO COMO PROTEÇÃO DOS DIREITOS DA PERSONALIDADE; 2 DIREITO AO ESQUECIMENTO NA INTERNET: A LEI 12.965/2014 - O MARCO CIVIL DA INTERNET - COMO LEI DE PROTEÇÃO DE DADOS; 3 DIREITOS DA PERSONALIDADE VERSUS DIREITO À LIBERDADE DE EXPRESSÃO, DIREITO À INFORMAÇÃO E DIREITO À MANIFESTAÇÃO DO PENSAMENTO COMO PARTE DO INTERESSE PÚBLICO: REQUISITOS PARA A APLICABILIDADE DO DIREITO AO ESQUECIMENTO; CONCLUSÃO; REFERÊNCIAS.

\section{INTRODUÇÃO}

Após o surgimento da internet, a evolução tecnológica se encontra em um momento incontrolável e incessável. Informações, dados e conteúdo de qualquer tipo são acessados de forma rápida, fácil e ilimitada pela rede virtual. Seja através do computador, seja através do smartphone, o usuário pode acessar tais informações e ler o seu conteúdo a qualquer hora que desejar e, além disso, a internet é um dos meios mais efetivos de difusão de informações em virtude de seu fácil acesso.

Todavia, nem todos os conteúdos informativos expostos na internet possuem e detém uma relevância social para com o que está sendo divulgado. Várias são as notícias que são consideradas “ultrapassadas" pela sociedade informativa e só vêm à tona para atingir ou garantir interesses de certos indivíduos, independentemente dos seus resultados, sejam benéficos ou maléficos. Neste sentido, o direito ao esquecimento surge como modo de tutela da memória individual para regrar a difusão dessas informações que não possuem caráter social-informativo, mas, pelo contrário, apenas atingir e gerar danos a uma determinada pessoa.

De um lado, existe o princípio do interesse público, corolário do estado democrático de direito e principal norma supra principiológica contra a censura prévia. De outro, têm-se os direitos da personalidade, os quais entram em antinomia com o princípio do interesse público quando a veiculação de dados, fatos ou informações, em tese, são para o atendimento informativo social.

Através deste aspecto, o presente artigo, utilizando-se da pesquisa bibliográfica e dos métodos empírico dialético, empírico generalizado e dedutivo, buscará uma conclusão lógica para a aplicação deste instituto no direito brasileiro e no direito comparado, solucionando e superando o problema da utilização do direito ao esquecimento através da apresentação de requisitos objetivos e subjetivos. 
Como modo de introdução, no primeiro tópico será abordada a origem e aplicação desse instituto no direito comparado, bem como será realizada uma interpretação hermenêutica de como este instituto será utilizado para a proteção e tutela dos direitos da personalidade. Após, no segundo tópico, far-se-á um estudo do direito ao esquecimento na Lei 12.965/2014, conhecida como Marco Civil da Internet, e um estudo legislativo para subsidiar sua aplicação. Por fim, no terceiro e último tópico, serão apresentados o conflito entre os direitos da personalidade e do interesse público, bem como os requisitos necessários para a aplicação do direito ao esquecimento, compatibilizando esse instituto e adequando-o ao sistema jurídico brasileiro e ao direito comparado.

\section{O DIREITO AO ESQUECIMENTO COMO PROTEÇÃO DOS DIREITOS DA PERSONALIDADE}

Fundado, basicamente, em um ensaio de Samuel Warren e Louis Brandels ${ }^{1}$, o direito ao esquecimento surge, na expressão right to be alone, com o ideal de privacidade em sua essência. Contudo, com as adaptações e evoluções jurídicas e sociais, as mudanças em seu conteúdo protecionista não poderiam seguir um caminho diferente.

Seu desenvolvimento inicial apresentou maior influência no Direito Penal, fundamentando e vedando o caráter perpétuo da pena (art. $5^{\circ}$, III e XLVII, b, da CF/88), fazendo com que esta, depois que totalmente exarada daqueles indivíduos que tenham a cumprido integralmente, não possa ser utilizada como forma de vincular o sujeito ao crime cometido, evitando, portanto, a cisão da memória do ato criminoso a ele para uma efetiva ressocialização e proteção dos seus direitos personalíssimos.

Autonomamente reconhecido no Brasil, no âmbito do Direito Privado, apenas em 2013 através do Enunciado 531 da VI Jornada de Direito Civil ${ }^{2}$ e do julgamento de um Recurso Especial no $\mathrm{STJ}^{3}$ - em virtude da grande disponibilidade de informações que, quando utilizadas de forma

\footnotetext{
1 WARREN, Samuel D.; BRANDEIS, Louis D. The Right to Privacy. Harvard Law Review, vol. 4. 1890. Disponível em: <http://faculty.uml.edu/sgallagher/Brandeisprivacy.htm> Acesso em: 21 out. 2016.

2 BRASIL. Justiça Federal. Enunciado 531 - A tutela da dignidade da pessoa humana na sociedade da informação inclui o direito ao esquecimento. Disponível em: <http://www.cjf.jus.br/cjf/corregedoriada-justica-federal/centro-de-estudos-judiciarios-1/publicacoes-1/jornadas-cej/vijornadadireitocivil2013web.pdf> Acesso em: 21 out. 2016.

3 BRASIL. Superior Tribunal de Justiça. Acórdão de decisão que negou provimento ao pedido de reexame dano moral. Recurso Especial $n^{\circ}$ 1.334-097. Globo Comunicações e Participações S/A e Jurandir
} 
errônea, causam um grande dano ao lesado -, o direito ao esquecimento, com base no art. 11 do Código Civil de 2002, que garante a proteção dos direitos da personalidade, foi adaptado ao nosso sistema jurídico para tutelar, como locus, a dignidade da pessoa humana e os direitos a ela inerentes. Tal garantia, de acordo com o enunciado 576 na VII Jornada de Direito Civil ${ }^{4}$, que é baseado em uma interpretação conforme o art. $5^{\circ}$, inciso XXXV, da Constituição Federal de 1988, poderá ser feita, inclusive, através de tutela judicial inibitória.

“A ideia de esquecimento está ligada diretamente ao pensamento da superação do passado, da redenção, possibilitando que o sujeito não tenha o seu direito à privacidade, à intimidade, ao nome, à honra, atingido por fatos já então consolidados no tempo" 5 . Assim, “o direito ao esquecimento é a possibilidade de defesa que, como uma redoma, permite a um particular que não autorize a veiculação ou retire desta um fato pretérito que o expõe ao público em geral, causando-lhe sofrimentos ou transtornos”.

Está em andamento no Supremo Tribunal Federal, tendo como matéria de repercussão geral o direito ao esquecimento, o Recurso Especial $833248^{7}$. Em síntese, trata-se de uma ação movida pelos familiares de Aida Curi, a qual faleceu em 1958, aos 18 anos de idade, brutalmente violentada e estuprada. Tal fato fora, após 50 anos do evento, divulgado novamente, sem autorização familiar, em rede nacional, fazendo com que, de acordo com a família, toda aquela situação desgastante e terrível retornasse à tona, atingindo-os novamente.

Em manifestação, a Procuradoria Geral da República aduz que:

não é possível, com base no denominado direito a esquecimento, ainda não reconhecido ou demarcado no âmbito civil por norma alguma do ordenamento jurídico brasileiro, limitar o direito fundamental à liberdade de expressão por

\footnotetext{
Gomes França. Relator: Min. Luís Felipe Salomão: 28 mai. 2013. Disponível em: <http://s.conjur.com.br/dl/direito-esquecimento-acordao-stj.pdf> Acesso em: 21 out. 2016.

${ }^{4}$ BRASIL. Justiça Federal. Enunciado 576 - 0 direito ao esquecimento pode ser assegurado por tutela judicial inibitória. Disponível em: <http://www.cjf.jus.br/cjf/corregedoria-da-justica-federal/centro-deestudos-judiciarios-1/publicacoes-1/jornadas-cej/vii-jornada-direito-civil-2015.pdf> Acesso em: 21 out. 2016.

${ }^{5}$ MARTINEZ, Pablo Dominguez. Direito ao esquecimento: a proteção da memória individual na sociedade da informação. Rio de Janeiro: Lumen Juris, 2014. p. 58.

${ }^{6}$ MARTINEZ, Pablo Dominguez. Direito ao esquecimento: a proteção da memória individual na sociedade da informação. Rio de Janeiro: Lumen Juris, 2014. p. 81.

7 BRASIL. Supremo Tribunal Federal. Acórdão de decisão que negou provimento ao instituto da repercussão geral. Recurso Extraordinário com Agravo $\mathrm{n}^{\circ}$ 833.248. Nelson Curi, et. al. e Globo Comunicações e Participações S/A. Relator: Min. Dias Toffoli. 20 fev. 2015. Disponível em: <http://www.stf.jus.br/portal/processo/verProcessoPeca.asp?id=302238926\&tipoApp=.pdf> Acesso em: 21 out. 2016.
} 
censura ou exigência de autorização prévia. Tampouco existe direito subjetivo a indenização pela só lembrança de fatos pretéritos. ${ }^{8}$

Em sentido adverso, como demonstrado anteriormente, o reconhecimento do direito ao esquecimento já fora realizado através de julgamentos pelo STJ e pelos enunciados das Jornadas de Direito Civil, tendo como fundamento a própria dignidade da pessoa humana e, como reforço, os direitos da personalidade, carecendo somente de regra expressa e explícita sobre o assunto. Contudo, tal justificativa não seria viável para sua inaplicabilidade.

0 avanço tecnológico é contínuo, mas a ausência de leis regulamentando o assunto, ainda mais no sistema jurídico brasileiro, é imensa. A falta de dispositivos legais para determinadas situações obriga os juízes e juristas a adequarem e interpretarem a Constituição conforme cada caso que thes é apresentado, observando os direitos em conflitos e determinando, em cada situação, através da hermenêutica e racionalidade jurídica, a aplicabilidade e precedência de um ou de outro direito, mas nunca absterem-se por não haver regra expressa sobre determinado assunto.

Recentemente, já um passo à frente do Brasil, “o direito ao esquecimento na União Europeia já pode ser aplicado para os usuários de internet, ou seja, aquele que utiliza da internet e tem seus dados divulgados e inscritos nela, poderá, a qualquer momento, requisitar que tais informações sejam deletadas" .

Todas essas ações, não só no direito brasileiro, como no direito comparado, no que tange ao direito ao esquecimento são, primeiramente, para tutelar os direitos da personalidade, em especial a honra, a imagem, o nome e a privacidade. A ideia de que tais direitos são intransmissíveis, irrenunciáveis e ou indisponíveis encontra-se em parte ultrapassada, visto que poderá ocorrer a cessão, ainda que parcial, por parte de quem os detêm, para os fins que melhor destinar. Todavia, será a invasão destes direitos, sem autorização daquele que for lesado, que será o objeto do direito ao esquecimento, este que, atualmente, não se limita somente à área e proteção desses direitos em processos criminais, mas também no mundo digital, na internet.

8 BRASIL. Supremo Tribunal Federal. Manifestação da Procuradoria Geral da República $\mathbf{N}^{\circ}$ 156.104/2016. Recurso Extraordinário com Agravo $n^{\circ}$ 833.248. Nelson Curi, et. al. e Globo Comunicações e Participações S/A. Disponível em: <http://www.stf.jus.br/portal/processo/verProcessoPeca.asp?id= 309953111\&tipoApp=.pdf $>$ Acesso em: 21 out. 2016.

9 PINHEIRO, Aline. Direito ao esquecimento para usuários da internet vira lei na União Europeia. Disponível em: <http://www.conjur.com.br/2016-abr-18/direito-esquecimento-internet-vira-lei-uniaoeuropeia> Acesso em: 21 out. 2016. 


\section{DIREITO AO ESQUECIMENTO NA INTERNET: A LEI 12.965/2014 - 0 MARCO CIVIL DA INTERNET - COMO LEI DE PROTEÇÃO DE DADOS}

É inegável que o avanço no alcance da internet proporcionou uma série de melhorias e comodidades aos seus usuários. "Todavia, as tecnologias da informação permitem que uma série de dados pessoais sejam armazenados de forma ilimitada e, a proteção destes, inclusive no Brasil, é precária”10. Essa precariedade e ausência legislativa para a proteção destes dados facilita sua circulação de forma livre e contínua através de pesquisas em motores de buscas (Google, Yahoo, Bing).

Esporadicamente, torna-se possível que, nessas pesquisas, dados privados, íntimos e sigilosos de pessoas que não desejam que essas informações estejam ao alcance de todos, durante um prazo indeterminado e ilimitado e globalmente divulgadas para o acesso, possam afetar os direitos da personalidade e, principalmente, sua honra e dignidade. ${ }^{11}$

É neste sentido então que o Marco Civil da Internet estabelece, em seu artigo $7^{\circ}, \mathrm{X}$, uma base legal para a proteção de dados, dando encalço para a aplicabilidade do direito ao esquecimento no sistema jurídico brasileiro. 0 conteúdo do inciso deste $\operatorname{artigo}^{12}$ aborda a exclusão definitiva dos dados pessoais, desde que requerida pelo usuário titular, quando as relações inter pars - sejam elas de consumo ou não - terminarem. Ou seja, o esquecimento está sendo utilizado como encalço legal para a proteção da privacidade, honra, nome e dignidade da pessoa que tem ali os seus dados gravados.

Ainda mais, a proteção destes dados não é problema só no Brasil:

Uma decisão recente de 13 de maio de 2014 do Tribunal de Justiça da União Europeia (TJUE) reconheceu o direito dos usuários da internet, e até aqueles que não a utilizam, sendo os cidadãos em geral, da exclusão e esquecimento de seus dados na Internet através de uma solicitação aos motores de busca (Google, Bing,

\footnotetext{
${ }^{10}$ MARTINEZ, Pablo Dominguez. Direito ao esquecimento: a proteção da memória individual na sociedade da informação. Rio de Janeiro: Lumen Juris, 2014. p. 56.

11 Ibidem, p. 57.

12 Art. $7^{\mathrm{O}} \mathrm{O}$ acesso à internet é essencial ao exercício da cidadania, e ao usuário são assegurados os seguintes direitos $[\ldots]$

$X$ - exclusão definitiva dos dados pessoais que tiver fornecido a determinada aplicação de internet, a seu requerimento, ao término da relação entre as partes, ressalvadas as hipóteses de guarda obrigatória de registros previstas nesta Lei;

BRASIL. Lei. 12.965, de 23 de abril de 2014. Marco Civil da Internet. Diário Oficial da República Federativa do Brasil. Brasília, DF: 23 abr. 2014. Art. $7^{\circ}$. Disponível em: <http://www.planalto.gov.br/ccivil_03/_ato2011-2014/2014/lei//12965.htm> Acesso em: 21 out. 2016.
} 
dentre outros) para que retirem os links que deem acesso a essas informações. A posição do Tribunal é a de que todo o indivíduo tem direito ao esquecimento e, quando tiver seus direitos violados, poderá pedir a remoção da Internet dos links que afetam esses direitos, ainda que seja verdade e legalmente publicado. ${ }^{13}$

Além disso, após dois anos desta decisão:

- Parlamento europeu aprovou uma regulamentação sobre o direito ao esquecimento que deverá ser tratada e aplicada por todos os países da União Europeia. Contudo, essa regulamentação ainda carece de critérios objetivos e subjetivos para sua aplicação no que tange às notícias jornalísticas. ${ }^{14}$

Todavia, ainda que haja uma pequena e escassa produção legislativa abordando o assunto de proteção de dados na internet, "as invasões à privacidade e os devassamentos de dados particulares por intermédio de diversos sistemas de registro e de informações existentes são constantes, disponibilizando-os na rede, no mundo negocial”15 e que, muitas vezes, fogem do controle jurídico em virtude da internet atravessar fronteiras de vários países.

Exemplo deste comércio de dados era o site "Tudo Sobre Todos" em que cada dado pessoal, desde o Cadastro de Pessoas Físicas (CPF) até o endereço residencial, poderia ser informado pelo site a partir da aquisição de um plano de dados ${ }^{16}$. Porém, depois de tornar-se de conhecimento da população através da mídia, o site saiu do $\operatorname{ar}^{17}$ e o Ministério Público Federal iniciou uma investigação, decidindo oferecer uma denúncia contra o site perante a Justiça Federal, a qual a acatou e determinou o bloqueio de acesso ao site até o final do curso do processo $^{18}$.

13 PINHEIRO, Aline. Europa decide que Google pode ser obrigado a filtrar buscas. Disponível em: <http://www.conjur.com.br/2014-mai-13/google-omitir-busca-pagina-ofensas-decide-uniao-europeia> Acesso em: 21 out. 2016.

${ }^{14}$ Ibidem.

${ }^{15}$ MACEIRA, Irma Pereira. A proteção do direito à privacidade familiar na internet. Rio de Janeiro: Lumen Juris, 2015. p. 133.

${ }^{16}$ VERAS, Leonardo. Seu nome, CPF e endereço podem estar disponíveis neste site sem que você saiba. Disponível em: <http://exame.abril.com.br/tecnologia/noticias/seu-nome-cpf-e-endereco-completospodem-estar-disponiveis-neste-site-sem-que-voce-saiba-disso> Acesso em: 21 out. 2016.

17 TREVIZAN, Karina. Site "Tudo Sobre Todos" sai do ar por parte dos usuários. Disponível em: <http://g1.globo.com/economia/noticia/2015/07/site-tudo-sobre-todos-sai-do-ar.html> Acesso em: 21 out. 2016.

${ }^{18}$ BRASIL. Ministério Público Federal. Justiça acata ação do MPF e determina retirada do ar do site Tudo Sobre Todos. Disponível em: <http://www.prrn.mpf.mp.br/grupo-asscom/noticias-internet/justica-acataacao-do-mpf-e-determina-retirada-do-ar-do-site-tudo-sobre-todos> Acesso em: 21 out. 2016. 
Para combater este tipo de ação, o art. $7^{\circ}$, nos incisos I, II, III, VII, VIII em suas alíneas $a, b$ e $c$, e IX, regula a inviolabilidade da intimidade e da vida privada, sendo passível de reparação por danos morais ou patrimoniais decorrente de sua violação. Regula, também, a inviolabilidade e sigilo no fluxo e armazenamento de suas comunicações, sejam privadas ou não, pela internet. Ou seja, todos os atos praticados dentro da rede, salvo por ordem judicial, são invioláveis, ainda que não sejam de caráter privado, pois este termo está ausente no inciso II, presente somente no inciso III.

Protege, além destes, o não fornecimento a terceiros de seus dados pessoais sem o livre consentimento, de forma expressa e informada, de quem o está cedendo, salvo, novamente, nas hipóteses legais. E, por fim, o inciso VII em suas alíneas diz da possibilidade de coleta, uso, armazenamento, tratamento e proteção de dados, desde que os façam de modo justificado, não sejam vedados pela legislação e estejam especificados no contrato de prestação de serviços ou nos termos de uso, devendo, de acordo com o inciso IX, as cláusulas que abordarem esses assuntos, estarem destacadas dentre as demais para, sob pena de violação dos direitos do usuário da internet, este poder concordar expressamente com as cláusulas ali aduzidas ${ }^{19}$.

Assim, após todo o exposto, o brocado de que “o que está na internet nunca será deletado" não pode ser válido, sob pena de violação de direitos fundamentais do homem.

Todas as proteções constitucionais e infraconstitucionais referentes aos direitos à intimidade e à privacidade encontram desafios para a sua aplicabilidade nos dias atuais, pois o

${ }^{19}$ Art. 7ํㅡ 0 acesso à internet é essencial ao exercício da cidadania, e ao usuário são assegurados os seguintes direitos:

I - inviolabilidade da intimidade e da vida privada, sua proteção e indenização pelo dano material ou moral decorrente de sua violação;

II - inviolabilidade e sigilo do fluxo de suas comunicações pela internet, salvo por ordem judicial, na forma da lei;

III - inviolabilidade e sigilo de suas comunicações privadas armazenadas, salvo por ordem judicial;

$[\ldots]$

VII - não fornecimento a terceiros de seus dados pessoais, inclusive registros de conexão, e de acesso a aplicações de internet, salvo mediante consentimento livre, expresso e informado ou nas hipóteses previstas em lei;

VIII - informações claras e completas sobre coleta, uso, armazenamento, tratamento e proteção de seus dados pessoais, que somente poderão ser utilizados para finalidades que:

a) justifiquem sua coleta;

b) não sejam vedadas pela legislação; e

c) estejam especificadas nos contratos de prestação de serviços ou em termos de uso de aplicações de internet;

IX - consentimento expresso sobre coleta, uso, armazenamento e tratamento de dados pessoais, que deverá ocorrer de forma destacada das demais cláusulas contratuais;

BRASIL. Lei. 12.965, de 23 de abril de 2014. Marco Civil da Internet. Diário Oficial da República Federativa do Brasil. Brasília, DF: 23 abr. 2014. Art. $7^{\circ}$. Disponível em: <http://www.planalto.gov.br/ccivil_03/_ato2011-2014/2014/lei/l12965.htm> Acesso em: 21 out. 2016. 
conceito de privacidade e intimidade em nosso mundo globalizado e inteiramente conectado difere do conceito de Warren e Brandels, feito no início do século XX, porém, a essência é a mesma, ou seja, a proteção destes direitos.

Uma das diferenças entre estes conceitos está na definição da área de atuação de cada um dos direitos nele protegidos para garantir sua inviolabilidade e, quando esta não for possível, critérios para sua indenização. Deste modo, ainda que haja coleta de dados de forma convencionada, com a finalização do contrato entre as partes, os dados pessoais ali guardados para aquela finalidade devem ser deletados a requerimento da parte ${ }^{20}$.

Tal previsão legal esboça, nitidamente, um suporte legal para reconhecimento e consagração do direito ao esquecimento no sistema jurídico brasileiro. Caso uma informação já tenha sido veiculada e atingido o seu fim, não há motivos para guardá-la correndo o risco de publicá-la novamente e, com isso, lesionar os direitos da personalidade a quem as informações foram ligadas.

Todavia, a Lei 12.965 de 2014 não protege só os direitos à intimidade e à privacidade. Garante, também, a liberdade de expressão, comunicação e manifestação do pensamento, nos termos da Constituição Federal $^{21}$. Será nesse paradoxo que a aplicação do direto ao esquecimento encontrar-se-á problemática. De um lado, os direitos constitucionais da personalidade e da dignidade humana. De outro, os princípios constitucionais da liberdade de expressão, comunicação e manifestação do pensamento.

\footnotetext{
${ }^{20}$ Art. $7^{\circ} 0$ acesso à internet é essencial ao exercício da cidadania, e ao usuário são assegurados os seguintes direitos:

$[\ldots]$

$X$ - exclusão definitiva dos dados pessoais que tiver fornecido a determinada aplicação de internet, a seu requerimento, ao término da relação entre as partes, ressalvadas as hipóteses de guarda obrigatória de registros previstas nesta Lei;

BRASIL. Lei. 12.965, de 23 de abril de 2014. Marco Civil da Internet. Diário Oficial da República Federativa do Brasil. Brasília, DF: 23 abr. 2014. Art. $7^{\circ}$. Disponível em: <http://www.planalto.gov.br/ccivil_03/_ato2011-2014/2014/lei/l12965.htm> Acesso em: 21 out. 2016.

${ }^{21}$ Art. $3^{\circ}$ A disciplina do uso da internet no Brasil tem os seguintes princípios:

I - garantia da liberdade de expressão, comunicação e manifestação de pensamento, nos termos da Constituição Federal.

BRASIL. Lei. 12.965, de 23 de abril de 2014. Marco Civil da Internet. Diário Oficial da República Federativa do Brasil. Brasília, DF: 23 abr. 2014. Art. $7^{\circ}$. Disponível em: <http://www.planalto.gov.br/ccivil_03/_ato2011-2014/2014/lei/l12965.htm> Acesso em: 21 out. 2016.
} 


\section{DIREITOS DA PERSONALIDADE VERSUS DIREITO À LIBERDADE DE EXPRESSÃO, DIREITO À INFORMAÇÃO E DIREITO À MANIFESTAÇÃO DO PENSAMENTO COMO PARTE DO INTERESSE PÚBLICO: REQUISITOS PARA A APLICABILIDADE DO DIREITO AO ESQUECIMENTO}

Antes de tudo, deve-se ter uma definição jurídica de privacidade e intimidade nos dias atuais levando em consideração sua área de atuação. Como se trata de uma área ampla e de difícil conceituação de forma exata em virtude de sua mutação relacionada ao tempo e época, o ideal de privacidade será exposto ao seu básico para, no mínimo, tentar delimitar sua abrangência.

Em busca dos conceitos de privacidade e intimidade nos dispositivos legais da Constituição Federal de 1988, do Código Civil de 2002, do Marco Civil da Internet ou em outras leis infraconstitucionais, frustra-se o jurista ao encontrar somente indicações e dispositivos objetivando a proteção destes direitos. O legislador não ousou em tentar conceituá-los, deixando este árduo serviço para os doutrinadores.

Primeiramente, conforme Nery:

intimidade é considerada a esfera mais reservada do indivíduo. Lá, suas informações pessoais encontram-se resguardadas para não chegar ao conhecimento alheio, tornando-se um campo inviolável, protegido infra e constitucionalmente, referindo-se, também, à própria imagem diante dos meios de comunicação em massa. ${ }^{22}$

Já a privacidade "situa-se no campo jurídico, são os atos humanos externos à intimidade, reservados pela própria pessoa ou pela sua natureza"23. Ou seja, seria a exteriorização de uma parte da intimidade em detrimento de um determinado grupo, local, ou qualquer atividade, seja ela de interação ou não, a título de vontade do indivíduo que decide realizá-la e demonstrar que aquele âmbito constitui sua privacidade.

\footnotetext{
${ }^{22}$ NERY, Ana Luiza B. de Andrade Fernandes. Considerações sobre os bancos de dados de proteção ao crédito no Brasil. In: NELSON NERY JUNIOR e ROSA MARIA DE ANDRADE NERY (Coordenadores) Doutrinas essenciais. Responsabilidade Civil. Direito fundamental à informação. Dever de informar. Informações cadastrais. Mídia, informação e poder. Internet. São Paulo: Revista dos Tribunais. 2010. Apud MACEIRA, Irma Pereira. A proteção do direito à privacidade familiar na internet. Rio de Janeiro: Lumen Juris, 2015. p. 63.

${ }^{23}$ MACEIRA, Irma Pereira. A proteção do direito à privacidade familiar na internet. Rio de Janeiro: Lumen Juris, 2015. p. 64.
} 
Para José Afonso da Silva, "o conjunto de informação acerca do indivíduo que ele pode decidir manter sob seu exclusivo controle, ou comunicar, decidindo a quem, quando, onde e em que condições, sem a isso poder ser legalmente sujeito" ${ }^{24}$ seria o conceito ideal de privacidade. Deste modo, "o direito à privacidade ou direito ao resguardo tem como fundamento a defesa da personalidade humana contra injunções ou intromissões alheias" 25 , bem como “engloba o direito do indivíduo ao controle da coleta e utilização de seus dados pessoais"

De outro lado, a liberdade de expressão, de acordo com Cavalieri Filho:

é compreendida como o direito de expor livremente uma opinião, um pensamento ou uma ideia que não seja estritamente relacionada com fatos, acontecimentos ou dados ocorridos, passando-se, também, em um mundo de ideias, sem necessariamente que estes sejam verídicos e imparciais, devendo respeitar, a toda evidência, a privacidade de outrem. ${ }^{27}$

Nos ideais de Ingo Sarlet,

a liberdade de expressão consiste, mais precisamente, na liberdade de exprimir opiniões, portanto, juízos de valor a respeito de fatos, ideias, portanto, juízos de valor sobre opiniões de terceiros etc. (...)

Para assegurar a sua máxima proteção e sua posição de destaque no âmbito das liberdades fundamentais, o âmbito de proteção das liberdades fundamentais, o âmbito de proteção da liberdade de expressão deve ser interpretado como o mais extenso possível, englobando tanto a manifestação de opiniões, quanto de ideais, pontos de vistas, convicções, criticas, juízos de valor sobre qualquer matéria ou assunto e mesmo proposições a respeito de fatos. Neste sentido, em princípio todas: as formas de manifestação, desde que não violentas, estão protegidas pela liberdade de expressão, incluindo "gestos, sinais, movimentos, mensagens orais e escritas, representações teatrais, sons, imagens, bem como as manifestações veiculadas pelos modernos meios de comunicação, como as mensagens de páginas de relacionamento, blogs etc.". ${ }^{28}$

Assim, seguindo o raciocínio do autor, o direito à liberdade de expressão é tão amplo que o direito à manifestação seria abarcado por ele, sendo este, então, considerado como uma de suas características, mas não perdendo a sua autonomia frente aos demais direitos ou carecendo de tutela jurídica mediante a sua violação.

\footnotetext{
${ }^{24}$ SILVA, José Afonso da. Comentário contextual à Constituição. 5. ed. São Paulo: Malheiros, 2008. p. 100.

${ }^{25}$ PAESANI, Liliana Minardi. Direito e Internet: liberdade de informação, privacidade e responsabilidade civil. São Paulo: Atlas, 2014, p. 34.

${ }^{26}$ MARTINEZ, Pablo Dominguez. Direito ao esquecimento: a proteção da memória individual na sociedade da informação. Rio de Janeiro: Lumen Juris, 2014, p. 53.

${ }^{27}$ CAVALIERI FILHO, Sérgio. Programa de responsabilidade civil. 11. ed. São Paulo: Atlas, 2014, p. 144.

${ }^{28}$ SARLET, Ingo Wolfgang. Direitos Fundamentais em espécie. In: SARLET, Ingo Wolfgang; MARINONI, Luiz Guilherme; MITIDIERO, Daniel. Curso de Direito Constitucional. 3. ed. São Paulo: Revista dos Tribunais, 2014, p. 446-461.
} 
No que tange ao direito à informação, também resguardado na Constituição Federal de 1988 em seu art. 5 , inciso XIV ${ }^{29}$, na Lei de Acesso à Informação (Lei 12.527, de 2011), bem como também tutelado pela Comissão Interamericana de Direitos Humanos no teor do art. $13^{\circ}$, tem como objetivo, em síntese, "buscar, receber e difundir informações e ideias de toda natureza, sem consideração de fronteiras, verbalmente ou por escrito, ou em forma impressa ou artística, ou por qualquer outro processo de sua escolha"30.

Assim, para José Afonso da Silva,

o direito de informar, como aspecto da liberdade de manifestação de pensamento, revela-se um direito individual, mas já contaminado de sentido coletivo, em virtude das transformações dos meios de comunicação, de sorte que a caracterização mais moderna do direito de comunicação, que especialmente se concretiza pelos meios de comunicação social ou de massa, envolve a transmutação do antigo direito de imprensa e de manifestação do pensamento, por esses meios, em direitos de feição coletiva. ${ }^{31}$

Desta forma, torna-se nítido o problema na tutela dos direitos da personalidade, em especial a imagem e a privacidade, quando em conflito com esses demais direitos e, para a aplicação efetiva do direito ao esquecimento, devem-se observar alguns critérios.

0 primeiro e basilar dos critérios é que a informação tenha sido veiculada em um motor midiático de grande circulação (Internet, TV, Jornais, Revistas etc.), seja local, regional, nacional ou internacional, facilitando o acesso de uma grande parte da população, sob pena de censura prévia caso a informação ainda não tenha se tornado de acesso ao público, a qual, como base de um Estado Democrático de Direito, é um atentado a própria democracia, devendo esta ser vedada.

Neste sentido, o art. 13, caput e inciso II, da Convenção Interamericana de Direitos Humanos $^{32}$, garante a liberdade de pensamento e de expressão, sendo o exercício destes direitos

${ }^{29}$ Art. $5^{\circ}$.

XIV - é assegurado a todos o acesso à informação e resguardado o sigilo da fonte, quando necessário ao exercício profissional.

BRASIL. Constituição Federal de 5 de outubro de 1988. Diário Oficial da União. Brasília: Senado Federal, 1988. Disponível em: <http://www.planalto.gov.br/ccivil_03/constituicao/constituicaocompilado.htm> Acesso em: 21 out. 2016.

${ }^{30}$ Convenção Especializada Interamericana sobre Direitos Humanos, San José, Costa Rica, 1969. Disponível em: <https://www.cidh.oas.org/basicos/portugues/c.convencao_americana.htm> Acesso em: 21 out. 2016.

31 SILVA, José Afonso da. Comentário contextual à Constituição. 5. ed. São Paulo: Malheiros, 2008. p. 110-111.

${ }^{32}$ Artigo 13. Liberdade de pensamento e de expressão

1. Toda pessoa tem direito à liberdade de pensamento e de expressão. Esse direito compreende a liberdade de buscar, receber e difundir informações e ideias de toda natureza, sem consideração de fronteiras, 
não sujeitos à censura prévia. Contudo, podem ser regradas mediante lei as responsabilidades ulteriores pela sua violação e utilização em excesso.

Pode-se dizer então “que a censura é a restrição prévia à liberdade de expressão, fazendo com que esta, quando vedada, remeta à ideia de um governo autoritário em que as informações que não são consideradas necessárias ou de interesse dos governantes são censuradas"33. Além disso, como "característica inerente ao direito à liberdade de expressão, têm-se uma presunção de inconstitucionalidade de todos os meios utilizados para realizar a censura, seja ele no âmbito privado ou público"34.

Nessa mesma linha, posiciona-se o Supremo Tribunal Federal ao julgar a Ação Direta de Inconstitucionalidade $4.815^{35}$, a qual requeria autorização prévia para a divulgação de biografias. Julgada procedente para afastar a necessidade de autorização para a publicação das biografias, o Supremo Tribunal Federal reconhece que a censura prévia ao direito à liberdade de expressão e manifestação do pensamento seria uma afronta ao Estado Democrático de Direito.

Como segundo requisito à aplicabilidade do direito ao esquecimento, a informação deve ter sido de "domínio e conhecimento público"36 à época publicada e não deve ter um interesse público atual e latente para conhecimento dessa notícia, pois, caso o tenha e seja feita a difusão nos trâmites legais, o direito de expressão e informação será precedente sobre aqueles direitos. "Como o direito ao esquecimento tutela a memória individual, toda vez que houver

verbalmente ou por escrito, ou em forma impressa ou artística, ou por qualquer outro processo de sua escolha.

2. O exercício do direito previsto no inciso precedente não pode estar sujeito a censura prévia, mas a responsabilidades ulteriores, que devem ser expressamente fixadas pela lei e ser necessárias para assegurar:

a) o respeito aos direitos ou à reputação das demais pessoas; ou

b) a proteção da segurança nacional, da ordem pública, ou da saúde 0 da moral públicas. In: Convenção Especializada Interamericana sobre Direitos Humanos, San José, Costa Rica, 1969. Disponível em: <https://www.cidh.oas.org/basicos/portugues/c.convencao_americana.htm> Acesso em: 21 out. 2016.

33 CANOTILHO, J. J. Gomes; MENDES, Gilmar Ferreira; SARLET, Ingo Wolfgang; STRECK, Lenio Luiz. Comentários à Constituição do Brasil. São Paulo: Saraiva, 2013, p. 275.

${ }^{34}$ CANOTILHO, J. J. Gomes; MACHADO, Jónatas E. M. Constituição e código civil brasileiro: âmbito de proteção de biografias não autorizadas. In: JÚNIOR, Antônio Pereira Gaio; SANTOS, Márcio Gil Tostes dos. Constituição Brasileira de 1988. Reflexões em comemoração ao seu $25^{\circ}$ aniversário. Curitiba: Juruá, 2014, p. 129.

${ }^{35}$ BRASIL. Supremo Tribunal Federal. Acórdão de decisão que deu procedência à Ação Direta de Inconstitucionalidade. Ação Direta de Inconstitucionalidade $n^{\circ}$ 4.815. Associação Nacional dos Editores de Livros. Relatora: Min. Cármen Lúcia. 10 jun. 2016. Disponível em: <http://www.stf.jus.br/arquivo/cms/noticianoticiastf/anexo/adi4815relatora.pdf> Acesso em: 21 out. 2016.

${ }^{36}$ MARTINEZ, Pablo Dominguez. Direito ao esquecimento: a proteção da memória individual na sociedade da informação. Rio de Janeiro: Lumen Juris, 2014. p. 175. 
interesse público na divulgação de certas informações, a tutela jurídica torna-se frágil sobre este direito em virtude da posição doutrinária e jurisprudencial conservadora brasileira"37.

Um dos problemas para a utilização deste critério é a insuficiência em delimitar o que seria o interesse público, bem como qual sua área de abrangência, o que seria de importância sobre a vida passada de um particular para o governo e para a população, e o quanto o interesse público deve adentrar dentro da esfera pessoal desse indivíduo.

Um dos exemplos da interferência da administração pública para a população com o particular é a decisão do Supremo Tribunal Federal em recurso extraordinário ${ }^{38}$ abordando a publicação dos nomes e dos vencimentos dos servidores públicos bem como as vantagens pecuniárias por eles recebidas. Neste caso, há a cessão parcial e expressa da intimidade em detrimento do interesse público, pois, ao ser efetivado no cargo, o funcionário público tem plena consciência de que representa a administração (princípio da impessoalidade) e que todos os atos da administração, salvo os sigilosos, devem ser publicados (princípio da publicidade). Contudo, este não é o caso para a aplicação do direito ao esquecimento, apenas um demonstrativo da legítima interferência estatal na vida do particular.

Como o interesse público possui uma grande área de abrangência, atuando também juntamente com os direitos à liberdade de informação e do direito à liberdade de expressão, em suma, o seu conceito deve valer para tais áreas também, não se limitando somente à administração pública. Todavia, eis aqui o problema maior. Como não há um consenso na definição do interesse público, tal critério ficará à arbítrio do magistrado para definir no caso concreto o que seria ou não de interesse público. Para Celso Antônio Bandeira de Mello:

o interesse público deve ser conceituado como a ligação entre o interesse público e o particular, sendo este sendo projetado sobre aquele, representando um ideal de bem-estar e segurança como conjunto de interesses individuais para com os coletivos em sua qualidade de membros da sociedade. ${ }^{39}$

\footnotetext{
${ }^{37}$ MARTINEZ, Pablo Dominguez. Direito ao esquecimento: a proteção da memória individual na sociedade da informação. Rio de Janeiro: Lumen Juris, 2014, p. 160-161.

38 BRASIL. Supremo Tribunal Federal. Acórdão de decisão que negou provimento à repercussão geral. Recurso Extraordinário n 652.777 RG / SP. Município de São Paulo e Ana Maria Andreu Lacambra. Relator: Ministro AYRES BRITTO. 16 set. 2011. Disponível em: <http://redir.stf.jus.br/paginadorpub/paginador.jsp?docTP=TP\&doclD=1902861> Acesso em: 21 out. 2016. ${ }^{39}$ Para Celso Antônio Bandeira de Mello: “o interesse público deve ser conceituado como o interesse resultante do conjunto dos interesses que os indivíduos pessoalmente têm quando considerados em sua qualidade de membros da Sociedade, e pelo simples fato de o serem". In: MELLO, Celso Antônio Bandeira de. Curso de Direito Administrativo. São Paulo: Malheiros, 2009, p. 61.
} 
Ainda que o conceito do ilustre jurista seja bem elaborado, torna-se falho, deixando aberturas para discricionariedades do juiz para quando for aplicá-lo, tornando-se um risco para o Estado Democrático de Direito com decisões que haja carência de fundamentações legais ou que não sejam baseadas em uma interpretação constitucional.

O próximo critério para a aplicação do direito ao esquecimento é que haja preservação do contexto original da informação pretérita. Como pré-requisito já abordado, a informação pretérita deverá ter sido de domínio público, não podendo sofrer alterações no seu conteúdo. Ou seja, "ainda que uma informação pretérita seja verídica mas apresentada de forma diferente daquela que fora publicada, a tutela do direito ao esquecimento também a atingirá"40, cabendo, também, a tutela a um ilícito penal, tendo como objeto a violação da honra do indivíduo. Assim, “caso a informação que se pretenda reavivar não esteja totalmente contextualizada, a jornada que conduz a possibilidade de veiculação informativa será interrompida e prevalecerá o direito ao esquecimento" ${ }^{41}$.

Outro critério para a aplicação efetiva do direito ao esquecimento concerne à preservação dos direitos da personalidade na rememoração ${ }^{42}$. Quanto e quando a informação pretérita for veiculada, “deve-se analisar a real necessidade de exposição dos direitos da personalidade do indivíduo ali envolvido e realizar uma interpretação hermenêutica de acordo com o caso concreto frente ao princípio da liberdade de informação para com o direito ao esquecimento" ${ }^{43}$.

\footnotetext{
${ }^{40}$ MARTINEZ, Pablo Dominguez. Direito ao esquecimento: a proteção da memória individual na sociedade da informação. Rio de Janeiro: Lumen Juris, 2014, p. 176.

${ }^{41}$ Ibidem, p. 178.

42 Ementa: PENAL. AGRAVO REGIMENTAL NO RECURSO ESPECIAL. FURTO QUALIFICADO. MAUS ANTECEDENTES. PERÍODO DEPURADOR. AFASTAMENTO. IMPOSSIBILIDADE. AGRAVO REGIMENTAL NÃO PROVIDO.

A jurisprudência desta Corte Superior é firme em assinalar que condenações transitadas em julgado há mais de cinco anos podem ser consideradas como maus antecedentes para efeito de fixação da pena-base. Quando os registros da folha de antecedentes do réu são muito antigos, admite-se o afastamento de sua análise desfavorável, em aplicação à teoria do direito ao esquecimento.

Não decorridos sequer seis anos do trânsito em julgado da condenação utilizada para caracterizar maus antecedentes, deve ser mantida a avaliação negativa da vetorial.

Agravo regimental não provido. (Grifo nosso)

BRASIL. Superior Tribunal de Justiça. Acórdão que negou provimento ao agravo regimental. Recurso Especial $n^{\circ}$ 1.578.033. Marcos Sebastião Chaves de Oliveira e Ministério Público do Estado do Rio de Janeiro. Relator: Ministro Rogério Schietti Cruz. 16 jun. 2016. Disponível em: <https://ww2.stj.jus.br/processo/revista/documento/mediado/?componente=ATC\&sequencial=62427601 \&num_registro=201600173604\&data=20160628\&tipo=5\&formato=PDF>Acesso em: 21 out. 2016.

${ }^{43}$ Para o autor, "a verificação de critérios que buscam conferir mecanismos mais seguros para propiciar balizas ao julgador no balanceamento entre a liberdade de informação e o direito ao esquecimento, passase ao exame da real necessidade de exposição dos direitos da personalidade no momento da divulgação da
} 
Dessa forma, se uma informação veiculada atinge radicalmente os direitos da personalidade do indivíduo lesado e por consequência não há mais nenhuma utilidade pública na divulgação daqueles dados, a tutela do direito ao esquecimento recairá sobre essa violação. “O objetivo deste critério seria a compatibilização entre o direito à liberdade de informação e os direitos da personalidade, devendo preponderar aquele somente quando o interesse público for maior que este" ${ }^{\prime 4}$.

E como último critério, deve-se observar a utilidade e atualidade da informação. “A utilidade, neste caso, deve remeter-se exclusivamente ao caráter de interesse público, dando um caráter substancial e real no dado que se pretende divulgar. Assim, não se deve confundir o interesse público de curiosidade pública” ${ }^{\text {45 }}$. Ainda, conforme Martinez:

aqueles fatos que foram relevantes e tiveram um grande impacto social podem e merecem ser rememorados; contudo, para que a rememoração seja realizada de forma legítima e protegida pelo direito à informação, a utilidade real da informação para e com a coletividade também deve ser evidente, sob pena de violarem os direitos da personalidade, em especial o direito ao esquecimento. ${ }^{46}$

Além disso, a atualidade da informação é essencial. Como o direito ao esquecimento trata-se da tutela da memória individual, fatos pretéritos, não abarcaria fatos considerados “recentes" pela sociedade. Portanto, o decurso do tempo da publicação original até sua republicação deverá ter um lapso temporal considerável, fazendo com que os dados se consagrem no tempo e não mais tenham utilidade pública.

informação", contudo, uma observação fora feita para realizar o confronto desses princípios através da hermenêutica jurídica constitucional, pois, como explicitado, como parte do interesse público, a liberdade de informação torna-se incluída neste conceito, ficando ao arbítrio do magistrado decidir conforme sua discricionariedade, o que seria, portanto, contra o ideal da hermenêutica constitucional. MARTINEZ, Pablo Dominguez. Direito ao esquecimento: a proteção da memória individual na sociedade da informação. Rio de Janeiro: Lumen Juris, 2014, p. 178.

${ }^{44}$ MARTINEZ, Pablo Dominguez. Direito ao esquecimento: a proteção da memória individual na sociedade da informação. Rio de Janeiro: Lumen Juris, 2014, p. 179.

${ }^{45} \mathrm{O}$ autor explica que o ser humano detém dois aspectos a ele inerentes: o aspecto externo, englobando as relações sociais, e o interno, que diz respeito ao seu caráter efetivamente individual. 0 aspecto privado se caracterizaria pela proteção à privacidade, devendo essa esfera ser protegida irrestritamente, fazendo com que a averiguação do interesse público e sua utilidade na informação que se pretende veicular sejam relativas à face externa do indivíduo. Assim, o autor, demonstrando em um julgamento do REsp 984.803ES, nas palavras da ministra Nancy Andrighi, a notícia que se divulga deve ter materialmente dados informativos ou educativos, não podendo ser boatos, especulações ou mexericos. MARTINEZ, Pablo Dominguez. Direito ao esquecimento: a proteção da memória individual na sociedade da informação. Rio de Janeiro: Lumen Juris, 2014, p. 180-184.

${ }^{46}$ MARTINEZ, Pablo Dominguez. Direito ao esquecimento: a proteção da memória individual na sociedade da informação. Rio de Janeiro: Lumen Juris, 2014, p. 178. 


\section{CONCLUSÃO}

Inegável seria a tutela dos direitos da personalidade em razão da hipossuficiência deste em relação ao interesse público. Incumbe, nesse passo, ao Judiciário tutelar, de forma a realizar uma interpretação hermenêutica da Constituição, tais direitos consagrados como um dos pilares da democracia.

Assim, o direito ao esquecimento, através do estudo demonstrado, já fora reconhecido e aplicado em várias instâncias no ordenamento jurídico brasileiro, fazendo com que sua difusão e aplicação na sociedade informativa sejam realizadas de forma efetiva e que a tutela do Judiciário recaia e aceite, de forma total, esse instituto como respaldo para proteção dos direitos da personalidade, superando o problema inicial do artigo e atingindo os objetivos propostos.

Demonstrado o âmbito de incidência dos direitos personalíssimos e do princípio do interesse público, de fato, conclui-se pela possibilidade da utilização e aplicação do direito ao esquecimento no Judiciário brasileiro. Tal conclusão se dá por uma interpretação conforme a própria Constituição Federal de 1988, com as legislações infraconstitucionais e acerca da posição jurisprudencial dos Tribunais Superiores, além do avanço tecnológico-social frente ao direito, este, ao qual, deve adequar-se para corresponder e regrar de forma eficiente e manter o direito de forma íntegra e coerente.

\section{REFERÊNCIAS}

BRASIL. Justiça Federal. Enunciado 531 - A tutela da dignidade da pessoa humana na sociedade da informação inclui o direito ao esquecimento. Disponível em:

<http://www.cjf.jus.br/cjf/corregedoria-da-justica-federal/centro-de-estudos-judiciarios1/publicacoes-1/jornadas-cej/vijornadadireitocivil2013-web.pdf> Acesso em: 21 out. 2016.

BRASIL. Justiça Federal. Enunciado 576 - 0 direito ao esquecimento pode ser assegurado por tutela judicial inibitória. Disponível em: <http://www.cjf.jus.br/cjf/corregedoria-da-justicafederal/centro-de-estudos-judiciarios-1/publicacoes-1/jornadas-cej/vii-jornada-direito-civil2015.pdf> Acesso em: 21 out. 2016.

BRASIL. Lei. 12.965, de 23 de abril de 2014. Marco Civil da Internet. Diário Oficial da República Federativa do Brasil. Brasília, DF: 23 abr. 2014. Art. $7^{\circ}$. Disponível em: 
<http://www.planalto.gov.br/ccivil_03/_ato2011-2014/2014/lei//12965.htm> Acesso em: 21 out. 2016.

BRASIL. Ministério Público Federal. Justiça acata ação do MPF e determina retirada do ar do site Tudo Sobre Todos. Disponível em: <http://www.prrn.mpf.mp.br/grupo-asscom/noticiasinternet/justica-acata-acao-do-mpf-e-determina-retirada-do-ar-do-site-tudo-sobre-todos> Acesso em: 21 out. 2016.

BRASIL. Supremo Tribunal Federal. Acórdão de decisão que deu procedência à Ação Direta de Inconstitucionalidade. Ação Direta de Inconstitucionalidade $n^{\circ} 4.815$. Associação Nacional dos Editores de Livros. Relatora: Min. Cármen Lúcia. 10 jun. 2016. Disponível em:

<http://www.stf.jus.br/arquivo/cms/noticianoticiastf/anexo/adi4815relatora.pdf> Acesso em: 21 out. 2016.

BRASIL. Supremo Tribunal Federal. Acórdão de decisão que negou provimento ao instituto da repercussão geral. Recurso Extraordinário com Agravo ${ }^{\circ}{ }^{\circ}$ 833.248. Nelson Curi, et. al. e Globo Comunicações e Participações S/A. Relator: Min. Dias Toffoli. 20 fev. 2015. Disponível em: <http: / / www.stf.jus.br/portal/processo/verProcessoPeca. asp?id=302238926\&tipoApp=.pdf > Acesso em: 21 out. 2016.

BRASIL. Supremo Tribunal Federal. Acórdão de decisão que negou provimento à repercussão geral. Recurso Extraordinário ${ }^{\circ}$ 652.777 RG / SP. Município de São Paulo e Ana Maria Andreu Lacambra. Relator: Ministro AYRES BRITTO. 16 set. 2011. Disponível em:

<http://redir.stf.jus.br/paginadorpub/paginador.jsp?docTP=TP\&doclD=1902861> Acesso em: 21 out. 2016.

BRASIL. Supremo Tribunal Federal. Manifestação da Procuradoria Geral da República N ${ }^{\circ}$ 156.104/2016. Recurso Extraordinário com Agravo n 833.248. Nelson Curi, et. al. e Globo Comunicações e Participações S/A. Disponível em:

<http://www.stf.jus.br/portal/processo/verProcessoPeca. asp?id=309953111\&tipoApp=.pdf > Acesso em: 21 out. 2016.

BRASIL. Superior Tribunal de Justiça. Acórdão de decisão que negou provimento ao pedido de reexame dano moral. Recurso Especial $n^{\circ}$ 1.334-097. Globo Comunicações e Participações S/A e Jurandir Gomes França. Relator: Min. Luís Felipe Salomão: 28 mai.2013. Disponível em: <http://s.conjur.com.br/dl/direito-esquecimento-acordao-stj.pdf> Acesso em: 21 out. 2016.

BRASIL. Superior Tribunal de Justiça. Acórdão que negou provimento ao agravo regimental. Recurso Especial $n^{\circ}$ 1.578.033. Marcos Sebastião Chaves de Oliveira e Ministério Público do Estado do Rio de Janeiro. Relator: Ministro Rogério Schietti Cruz. 16 jun. 2016. Disponível em: <https://ww2.stj.jus.br/processo/revista/documento/mediado/?componente=ATC\&sequencial= 62427601\&num_registro=201600173604\&data=20160628\&tipo=5\&formato=PDF $>$ Acesso em: 21 out. 2016.

CANOTILHO, J.J. Gomes; MENDES, Gilmar Ferreira; SARLET, Ingo Wolfgang; STRECK, Lenio Luiz. Comentários à Constituição do Brasil. São Paulo: Saraiva, 2013.

CAVALIERI FILHO, Sérgio. Programa de responsabilidade civil. 11. ed. São Paulo: Atlas, 2014. 
Convenção Especializada Interamericana sobre Direitos Humanos, San José, Costa Rica, 1969. Disponível em: <https://www.cidh.oas.org/basicos/portugues/c.convencao_americana.htm> Acesso em: 21 out. 2016.

MACEIRA, Irma Pereira. A proteção do direito à privacidade familiar na internet. Rio de Janeiro: Lumen Juris, 2015.

MARTINEZ, Pablo Dominguez. Direito ao esquecimento: a proteção da memória individual na sociedade da informação. Rio de Janeiro: Lumen Juris, 2014.

MELLO, Celso Antônio Bandeira de. Curso de Direito Administrativo. São Paulo: Malheiros, 2009.

MITIDIERO, Daniel. Curso de Direito Constitucional. 3. ed. São Paulo: Revista dos Tribunais, 2014.

PAESANI, Liliana Minardi. Direito e Internet: liberdade de informação, privacidade e responsabilidade civil. São Paulo: Atlas, 2014.

PINHEIRO, Aline. Direito ao esquecimento para usuários da internet vira lei na União Europeia. Disponível em: <http://www.conjur.com.br/2016-abr-18/direito-esquecimentointernet-vira-lei-uniao-europeia> Acesso em: 21 out. 2016.

PINHEIRO, Aline. Europa decide que Google pode ser obrigado a filtrar buscas. Disponível em: <http://www.conjur.com.br/2014-mai-13/google-omitir-busca-pagina-ofensas-decide-uniaoeuropeia> Acesso em: 21 out. 2016.

SILVA, José Afonso da. Comentário contextual à Constituição. 5. ed. São Paulo: Malheiros, 2008.

TREVIZAN, Karina. Site “Tudo Sobre Todos" sai do ar por parte dos usuários. Disponível em: <http://g1.globo.com/economia/noticia/2015/07/site-tudo-sobre-todos-sai-do-ar.html> Acesso em: 21 out. 2016.

VERAS, Leonardo. Seu nome, CPF e endereço podem estar disponíveis neste site sem que você saiba. Disponível em: <http://exame.abril.com.br/tecnologia/noticias/seu-nome-cpf-eendereco-completos-podem-estar-disponiveis-neste-site-sem-que-voce-saiba-disso> Acesso em: 21 out. 2016.

WARREN, Samuel D.; BRANDEIS, Louis D. The Right to Privacy. Harvard Law Review, vol. 4. 1890. Disponível em: <http://faculty.uml.edu/sgallagher/Brandeisprivacy.htm> Acesso em: 21 out. 2016.

Recebido em: 24/10/2016 / Aprovado em: 04/03/2017 